Kalpa Publications in Civil Engineering
Volume 1, 2017, Pages 45-50
$\begin{gathered}\text { ICRISET2017. International Conference on Re- } \\ \text { search and Innovations in Science, Engineering } \\ \text { \&Technology. Selected papers in Civil Engineering }\end{gathered}$

\title{
A BIM Based Lighting Analysis for Evaluating Saving Potential in Lighting Cost During Project Cycle
}

\author{
Akash Shah $^{1}$, Pranav Chovatiya ${ }^{2}$, Niyati Shah ${ }^{3}$ \\ ${ }^{1}$ Assistant Professor, Department of civil engineering, DDIT, Nadiad, India \\ ${ }^{2} \mathrm{M}$. Tech (CE\&M) student, BVM Engineering college, Anand, India \\ ${ }^{3}$ Planning Engineer, SAI-SYSTRA consultancy Pvt. Ltd, Ahmedabad, India
}

\begin{abstract}
In today's world, it is very difficult to manage the complex construction project with traditional project management system. BIM (Building Information Modelling) is one of most useful recent development in Construction Industry which helps in visualizing virtual building model to find future defects in design, to reduce cost, to increase productivity and quality etc. Big projects are required to carry out work during night also. So, it becomes vital to provide sufficient Lighting considering economics as well. With the use of BIM, the saving potential in lighting cost can be found out. In this research paper one case study of lighting analysis of residential project is taken which shows the benefits in energy cost savings.

Keywords - BIM (Building Information Modelling), Lighting Analysis, 3D Model, Revit Architecture Software
\end{abstract}

\section{Introduction}

Construction Industry is an essential element for nation's infrastructure and individual growth. In today's world, it is very difficult to manage the complex project with traditional project management system. To remain competitive in the industry it is necessary to improve traditional practices by using new innovative tools. BIM (Building Information Modelling) is one of most useful recent development in Construction Industry which helps in visualizing virtual building model to find future defects in design, to reduce cost, to increase productivity and quality etc.

Big projects are required to carry out work during night also. In today's competitive world, it is required to find unnecessary cost during construction. So, in that case quantifiable predictions could aid to identify strategies and methods for improving building energy efficiency. Traditional thumb rules are inadequate to evaluate performance of building because (1) it may include simplified 
assumptions based on thumb rules which can be inaccurate. (2) it may force an aesthetic feature without considering performance impacts. (3) it may not provide performance evaluation of a certain design solution. [1]

BIM has an ability to estimate and predict the performance of building model by simulation and analysis of actual measurable data. BIM can produce an evaluation of multiple design alternatives. In order to evaluate and optimize building operation cost, it becomes vital to provide sufficient Lighting considering economics as well.

\section{Literature Survey}

The following are the literature review of past research papers on BIM and Energy saving analysis.

Bazjanac V. et al. (2005) carried out that for obtaining effective and reliable cost and energy performance results, it was necessary for U.S. GSA to use BIM. Building and industry data model based BIM would ease in importing data and reusing data and also help in detecting early error prior to design and construction. [4]

Howell I. et al. (2005) suggested that BIM has capacity to develop every building elements and coordinating each of them with source of all information of building within one database. BIM helps to identify any changes that were made to design earlier. [8]

Chaisuparasmikul P. et al. (2006) explored virtual model interface for efficient use of building data for visualization and energy simulation. He suggested that BIM aids AEC industry in visually analyzing energy performance of building with dynamic changes of climate and building parameters. BIM is beneficial for sustainable design of building. [5]

Huang Y. C. et al. (2008) developed a scalable lighting simulation tool to achieve a high-quality design, to ensure holistic design decisions, lighting simulation in actual building projects which supports effective design processes. Using this simulation tool lighting simulation can be carried out with minimum time and effort. [9]

Azhar S. et al. (2010) studied that BIM can help in providing sustainable design of building. For sustainable design of building projects, BIM aids to take early decision in planning and design phase. Due to increase in cost and environmental problems, use of BIM can be beneficial for effective decision making [2]

Azhar S. et al. (2011) studied that BIM can be used for all phases of projects which helps AEC industry to visualize what is to be built in a simulated environment and to identify early defects related to design, construction or maintenance of facility. [3]

Moon H. J. et al. (2011) stated that to perform efficient building performance analysis interoperability between a BIM based architectural model and analysis programs is required. Architecture building model is linked with the energy analysis tool to measure the performance of project. Traditional methodology of energy analysis is based on past thumb rules and doesn't provide effective solutions. BIM can be used in early planning phase to reduce energy consumption of building. [10]

Dubois M. C. et al. (2011) carried out literature study on Strategies for effective usage of electrical lighting. He stated that Cost effective energy saving may be achieved by simply replacing and planning the electrical lighting installation. [7]

Aksamija A. et al. (2012) experimented a case study from an architectural practice on how BIM design models can be usedfor building performance analysis, focusing on orientation and shading studies, the performance of shading devices, solar access analysis and daylight simulation. [1] 
Dong B. et al. (2014) showed application of energy Fault Detection and Diagnostics (FDD) to effectively maintain building energy performance during the lifecycle of the building with correction applied to faults. [6]

Volk R. et al. (2014) studied various literature review based on BIM for existing buildings which promises benefits of BIM to overwhelm uncertainties of building condition and to handle efficient documentation prevailing in existing buildings. [11]

\section{Research Objectives}

This study is aimed for following objectives:

- To study the application of BIM technology to evaluate saving potential in energy.

- To analyze required lighting facilities for construction work during night phase.

- To evaluate saving potential in lighting cost of construction at night phase.

- To identify and bring down the unnecessary cost of project during construction work.

\section{Methodology}

The following steps are carried out to analyze and find saving potential of lighting cost during construction at night shift.

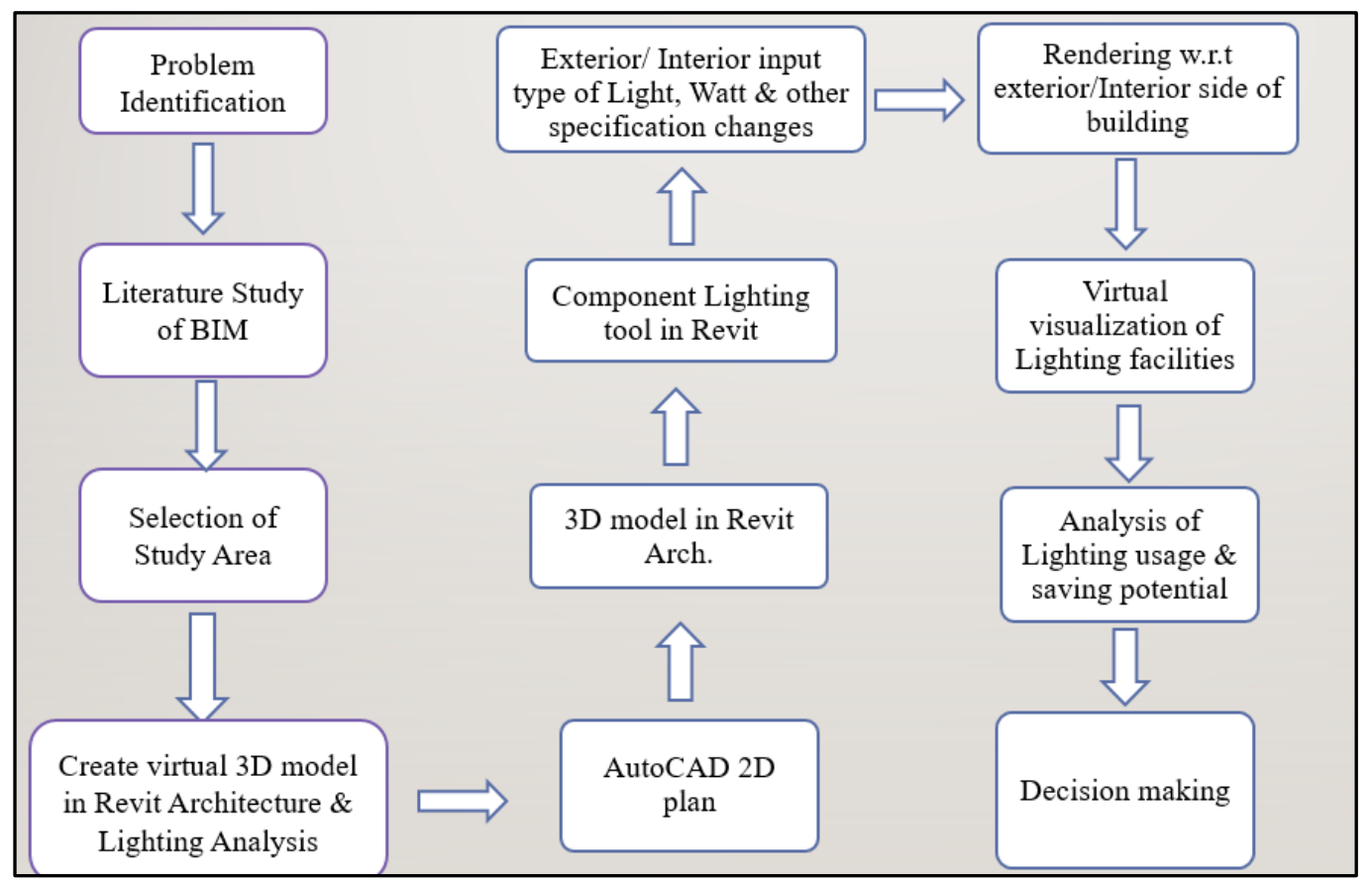

FIG. 1. Methodology of lighting analysis using BIM 


\section{Study Area}

A residential project - Madhav homes, vastral, Ahmedabad by Madhav Group is taken for the case study.

The proposed model is developed using Revit architecture'14. Initially C-5 tower (plinth under construction) fixed 6 METAL HALIDES (400 Watts) lamps which were reduced to 4 after this analysis.

This analysis was carried out using REVIT ARCHITECTURE, 2014 rendered images. From fig. 2 And fig. 3, it is cleared that the use of 4 metal halide lamps instead of 6 metal halide lamps gives the same lighting facilities which required to carry out work at exterior side of building.

Here, for external work 2 no's $-400 \mathrm{~W}$ bulb was reduced after this analysis.

\section{So, for 1 month lighting cost saving $=38.4 * 30 * 2$$$
=2304 \text { Rs } /-
$$

For large project having long duration \& cost such analysis becomes useful.

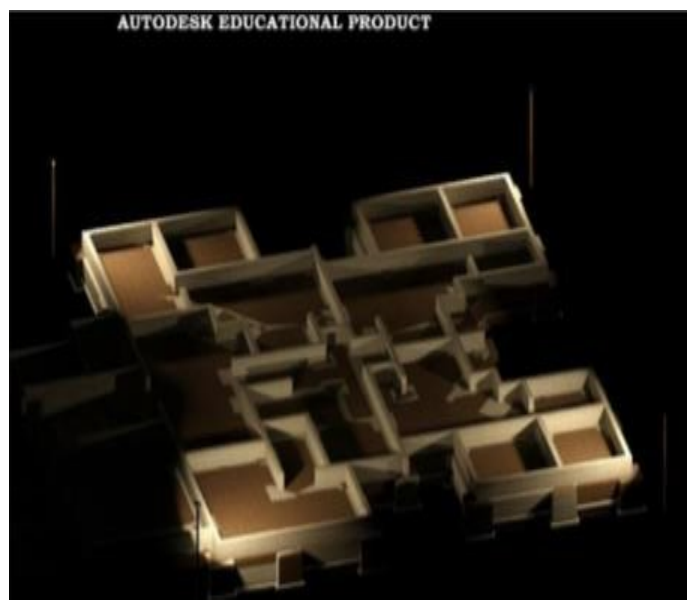

Fig.2. Using 4-Metal Halide Lamps: (400 Watts)

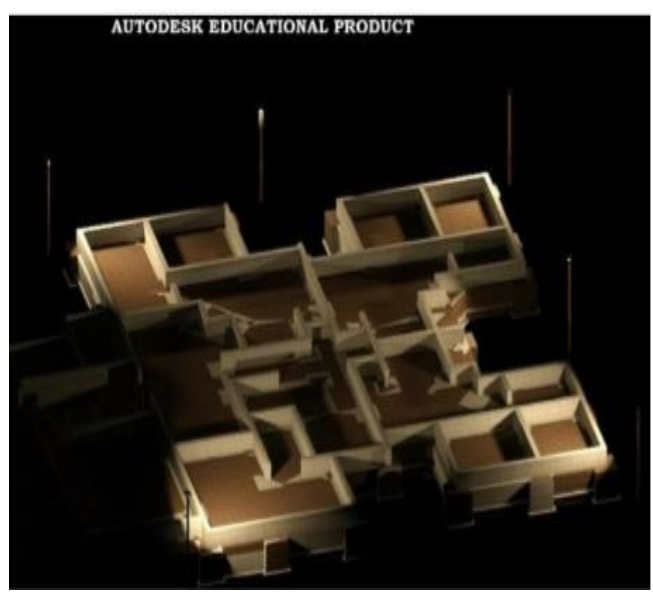

Fig.3. Using 6-Metal Halide Lamps: (400 Watts)

Secondly the internal building works were carried out using a 400 Watts lamps which can be replaced by lesser power consuming lamps for economy purpose as illuminance of 150 Watts lamps is sufficient.

From fig. 4 And fig. 5, it is cleared that the use of 150watt lamp instead of 400watt lamp gives the desired lighting facility near interior work site.

Data required from analysis were available from the lamp manufacture manual which were feed in the properties tab of REVIT ARCHITECTURE.

- $\quad$ Single 400 Watts bulbs consumes $0.40 \mathrm{KWH}$ per hour.

- $\quad$ Single 150 Watts bulbs consumes $0.15 \mathrm{KWH}$ per hour.

- Cost of unit per hour: 12 Rs. /unit (approx.)

- Night Shift duration: 8 hours.

- Cost of running a 400W bulb per day: 38.4 Rs. /day. 
- $\quad$ Cost of running a $150 \mathrm{~W}$ bulb per day: 14.4 Rs. /day.

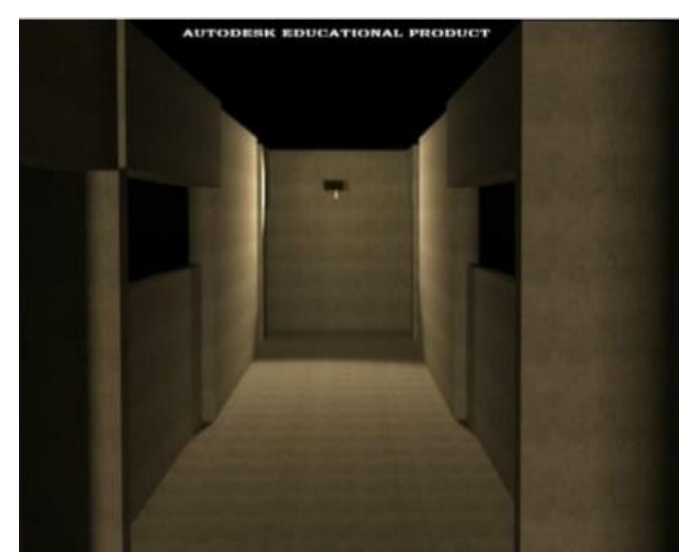

Fig. 4. 150 Watt- Metal Halide Lamp for Corridors

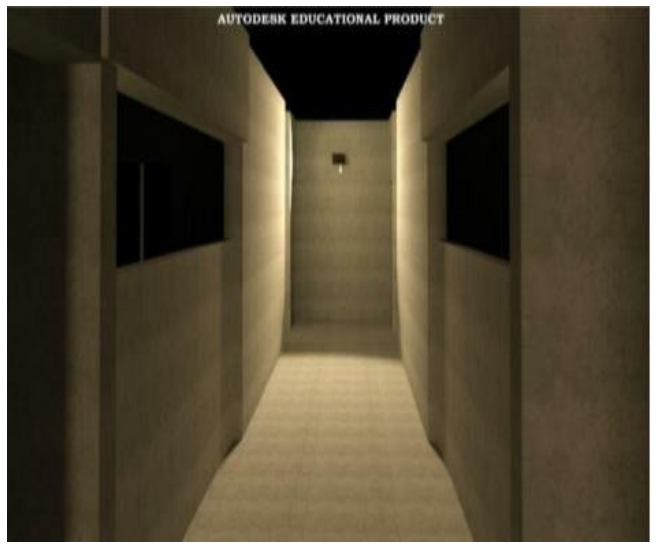

Fig. 5. 400 Watt- Metal Halide Lamp for Corridors

- For internal works if 400 Watts lamp is replaced by $150 \mathrm{Watts}, 20.0 \mathrm{Rs}$. /day can be saved per single lamp.

Here, 50 no's $-400 \mathrm{~W}$ bulb was reduced after this analysis.

So, for 1 month lighting cost saving

$=(38.4-14.4) * 30 * 50$

$=36000$ Rs $/$ - for 1 tower of building.

After replacing bulb, furthermore it was discussed with the project manager related to efficiency of lighting facilities during night construction. It was all found to be ok.

\section{Conclusion}

This study evaluates the use of BIM in lighting analysis for evaluating saving potential of lighting cost. Here overall lighting cost is being reduced by replacing high voltage bulb with low voltage bulb as per the requirement of work. This analysis will help in saving construction operation cost by reducing annual light bill cost and also help in energy saving. For large construction project, to bring down the cost of construction lighting analysis will be useful. It serves as a decision tool for identifying unnecessary lighting cost. furthermore, study and application of BIM in sustainable building should be explored. 


\section{References}

[1] Aksamija, A. (2012). "BIM-based building performance analysis: Evaluation and simulation of design decisions." Proceedings of the 2012 ACEEE Summer Study on Energy Efficiency in Buildings.

[2] Azhar, S. (2011). "Building information modeling (BIM): Trends, benefits, risks, and challenges for the AEC industry." Leadership and Management in Engineering 11(3): 241-252.

[3] Azhar, S., et al. (2010). A case study of building performance analyses using building information modeling. Proceedings of the 27th international symposium on automation and robotics in construction (ISARC-27), Bratislava, Slovakia.

[4] Bazjanac, V. (2005). Model based cost and energy performance estimation during schematic design. 22nd Conference on Information Technology in Construction.

[5] Chaisuparasmikul, P. (2006). Bidirectional Interoperability Between CAD and Energy Performance Simulation Through Virtual Model System Framework. Proceedings: ACADIA.

[6] Dong, B., et al. (2014). "A BIM-enabled information infrastructure for building energy Fault Detection and Diagnostics." Automation in Construction 44: 197-211.

[7] Dubois, M.-C. and Å. Bolsterer (2011). "Energy saving potential and strategies for electric lighting in future North European, low energy office buildings: A literature review." Energy and Buildings 43(10):

$$
2572-2582 \text {. }
$$

[8] Howell, I. and B. Batcheler (2005). "Building information modeling two years later-huge potential, some success and several limitations." The Laiserin Letter 22: 4.

[9] Huang, Y. C., et al. (2008). A scalable lighting simulation tool for integrated building design. Third National Conference of IBPSA-USA, July 30-August 1, 2008, Berkeley, California.

[10] Moon, Hyeun Jun, et al. "Case studies for the evaluation of interoperability between a bim based architectural model and building performance analysis programs." Proceedings of 12th Conference of International Building Performance Simulation Association. 2011.

[11] Volk, R., et al. (2014). "Building Information Modeling (BIM) for existing buildings-Literature review and future needs." Automation in Construction 38: 109-127. 